Research Article

\title{
Feeling the blues, seeing the blues
}

\section{Abstract}

Small research study showing that patients with depression have difficulties differentiating color hues
Volume 4 Issue 2 - 2016

\section{Ghassan George Hadda}

Clinical Neurophysiology,American Board of Psychiatry and Neurology, Lebanon

Correspondence: Dr. Ghassan George Haddad, Clinical Neurophysiology,American Board of Psychiatry and Neurology, Belle Vue Medical Center, Lebanon,

Email topneuro2003@yahoo.com

Received: December 03, 2015 | Published: January 29, 2016

\section{Introduction}

We noticed that patients with major depressive disorder referred to the Neurology department when suspected of having multiple sclerosis frequently have difficulty in reading the Ishihara color plates designed to assess the optic nerve function. We set up creating a simple bedside test to assess their color vision with depression before therapy and after their depression had been treated and to see if we can assess the degree of depression objectively based on our test.

\section{Method}

We created 10 different plates. We called them the depression plates and each plate was colored in blue. The only differences were the degree of hues each plates had and we numbered them from one to 10 with plate number one having 129 hues and plate number ten having 138 hues. (See samples of the different color plates).

40 patients were enrolled: 20 patients with untreated major depressive disorder and 20 patients with no mental health issues. All patients were tested for the Depression Plates. We asked our patients if they saw any difference in the color of the plates and then we asked them to put them in the order of color hues if they answered the first question correctly.

The test was done before anti-depressant therapy and 3,6 and 12 months after therapy 10 color plates numbered from one to ten and hues from 129-138 written on the back of the plates.

\section{Question one}

Do you see a difference between these plates?

If the patients responded by Yes,

We asked them to arrange the plates in order of hue.

The plate should get into a natural order so that the colors appear to change gradually in steps from the blue with lighter hue to the blue with the darkest hue.

Insert color plates hear.

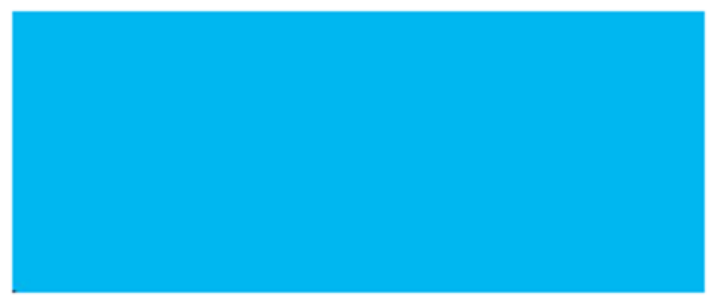

Color plate I -hue 129

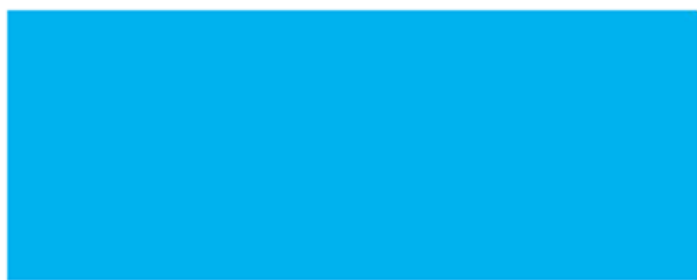

Color plate 2 -hue 130

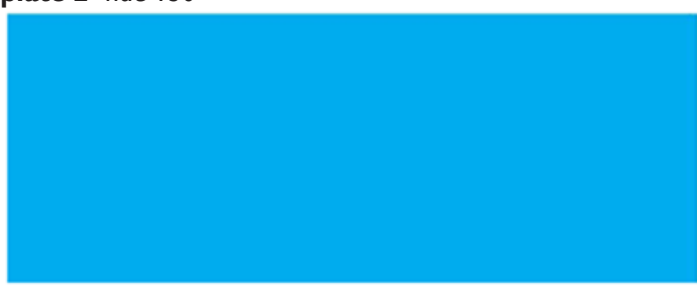

Color plate 3 -hue I3I

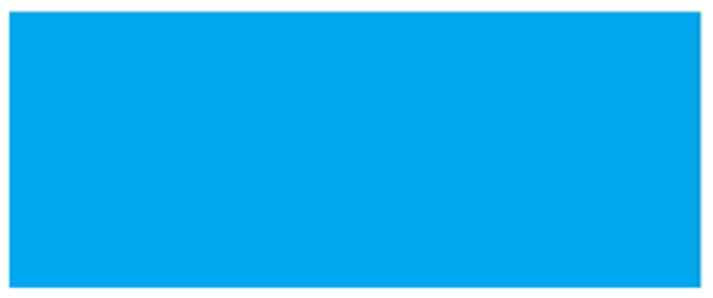

Color plate 4 -hue 132

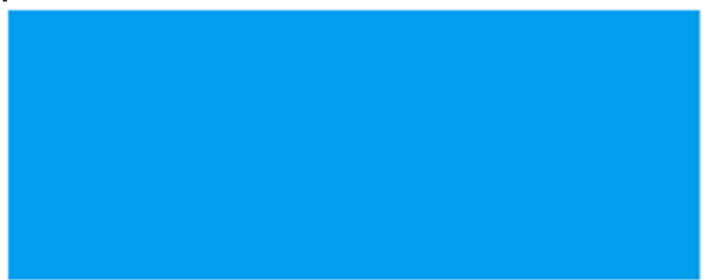

Color plate 5 -hue 133

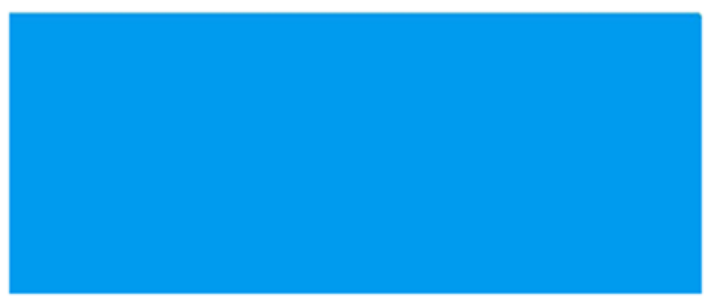

Color plate 6 -hue 134 


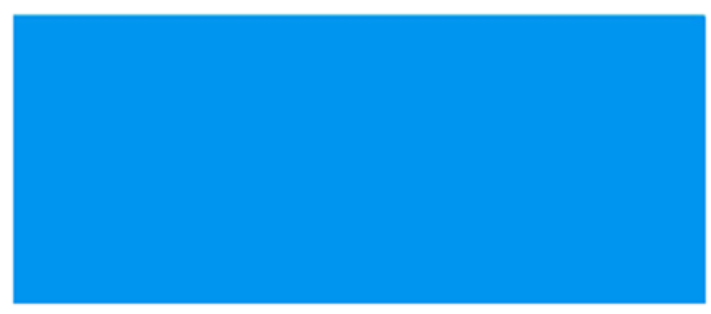

Color plate 7 -hue I 35

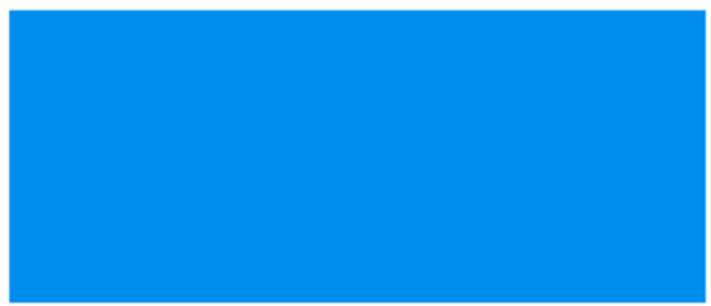

Color plate 8 -hue 136

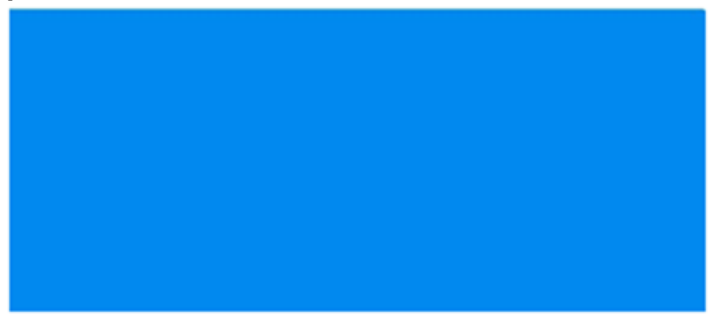

Color plate 9 -hue 137

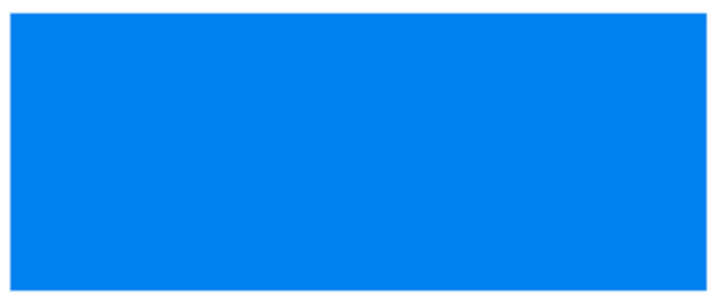

Color plate 10 -hue 138

\section{Results}

We found a strong and significant association between the severity of the depression and the color differentiation response suggesting that the more depressed the patient was, the less he was able to see the difference in the plates. Once the depression responded the number of correct colored plates identified increased dramatically and continued to increase with time of therapy.

The responses at 12 months were the best.

It was noted that depressed patients displayed dramatically lower retinal contrast gain as shown on pattern electroretinogram as reported by Emanuel Bubl but to our knowledge this is the first simple bedside objective test to assess major depressive disorder and its response to therapy.

\section{Acknowledgments}

None.

\section{Conflicts of interest}

None.

\section{References}

1. Hyett M, Parker G. Loss of light in the eyes: a window to melancholia Med Hypotheses. 2013;81(2):186-191.

2. Bubl E, Kern E, Ebert D, et al. Seeing Gray When Feeling Blue? Depression Can Be Measured in the Eye of the Diseased. Biol Psychiatry. 2010;68(2):205-208. 